\title{
A new aspect of advantage on uniportal video-assisted thoracic surgery for lung cancer
}

\author{
Kyoji Hirai ${ }^{1}$, Jitsuo Usuda ${ }^{2}$ \\ ${ }^{1}$ Divison of Thoracic Surgery, Nippon Medical School, Chiba Hokusoh Hospital, Chiba, Japan; ${ }^{2}$ Division of Thoracic Surgery, Nippon Medical \\ School, Tokyo, Japan \\ Correspondence to: Kyoji Hirai, MD, PhD. Division of Thoracic Surgery, Nippon Medical School Chiba Hokusoh Hospital, 1715 Kamakari, Inzai, \\ Chiba 270-1674, Japan. Email: ky-hirai@nms.ac.jp. \\ Comment on: Al-Ameri M, Sachs E, Sartipy U, et al. Uniportal versus multiportal video-assisted thoracic surgery for lung cancer. J Thorac Dis \\ 2019;11:5152-61.
}

Submitted Mar 18, 2020. Accepted for publication Apr 15, 2020.

doi: $10.21037 /$ jtd-20-1386

View this article at: http://dx.doi.org/10.21037/jtd-20-1386

In surgical treatment of lung cancer, uniportal videoassisted thoracic surgery (U-VATS) has been gradually increasing as a minimally invasive surgical treatment, as well as robot assisted thoracic surgery (RATS), in thoracic surgery. Reports on several treatment outcomes of U-VATS suggest that, at present, at least, perioperative complications, mortality, and early recurrence after surgery may be comparable to those of conventional multiportal VATS (M-VATS) (1-3). Although there have been fewer reports on the prognosis, outcomes of early non-small cell lung cancer comparable to those acquired by M-VATS may increase based on our experience.

In this report, the comparative study of the short-term treatment outcome of lung cancer between U-VATS and M-VATS performed at the Karolinska Institute in Sweden is demonstrated (4). The study design was an institutional observational cohort study, and interestingly carcinoid accounted for $8-9 \%$ of the surgical cases in both groups that were included pathological stage I to IV. The disease stage was more than IIIA in $8.2 \%$ in the U-VATS group, being higher than that $(4.7 \%)$ in the M-VATS group. Preoperative chemotherapy or radiotherapy was performed in 3.3 and $1.9 \%$ of all cases in the U-VATS and M-VATS groups, respectively. Figure 3 shows the 2-year survival rate in the U-VATS and M-VATS groups. The survival rate was slightly lower in the M-VATS group.

Early recovery after surgery, postoperative wound pain relief, and the esthetic satisfaction of patients are considered advantages of U-VATS, compared to those of M-VATS, but questions remain whether there is a statistically significant difference. In our study on a comparison of the wound pain relief effect between the 2 surgical procedures, a significant difference was noted in the wound pain relief effect on postoperative month 2 and thereafter, rather than early after surgery (5). The most important point is that a higher rate of direct discharge to home after surgery in the U-VATS than M-VATS group was presented in this report, but data on the presence or absence of the postoperative use of anti-inflammatory analgesics and opioid analgesics considered to be related to the rate of direct discharge to home after surgery, surgical factors (operative time and blood loss, etc.), and data on wound pain relief were not disclosed and it would have been better to describe comments on the reason for the presence of reoperation by U-VATS performed in approximately $5 \%$. Moreover, in the Karolinska Institute, postoperative management is performed following the protocol termed enhanced recovery after thoracic surgery (ERATS). Consequently, due to introduction of this protocol, the rate of direct discharge to home was $76.2 \%$ in the U-VATS group, being clearly higher than that $(62.1 \%)$ in the M-VATS group, and observation of the significance in the U-VATS group based on this postoperative low-invasiveness evaluation method was emphasized as a new finding. On the other hand, as recently reported by $\mathrm{Ng}$ et al. (6), there was no difference in the duration of hospital stay after surgery [length of stay (LOS)] between U-VATS and M-VATS. 
Apparently, regarding the indexes as less invasive surgery as the rate of discharge to home and the duration of LOS, it seems equal. However, there is an opinion that it cannot be concluded that a short LOS is equal to low-invasiveness or an index of excellent postoperative management because LOS can be influenced by various medical healthcare systems and medical insurances in hospitals at various countries. In this study, U-VATS significantly reduced the proportion of discharge to home compared to M-VATS because of reason that it might be a result of the launch of a protocol of ERATS (4). This may be a new finding acquired by the new evaluation method for minimally invasive surgery in hospital that is introduced to ERATS. However, as for ERATS, another study examining VATSspecific and thoracotomy-specific ERATS protocols, ERATS decreased LOS by two days in thoracotomy group (7). Brunelli et al. showed no significant benefit of ERATS in patients undergoing VATS segmentectomy or lobectomy (8). After the implementation of ERATS protocol, no LOS difference could be also found in other studies after M-VATS. Similarly, there was no difference of postoperative hospital stay in patients undergoing U-VATS and M-VATS in Karolinska institute introduced ERATS. Although it was reported from a single institute promoting the treatment protocol for ERATS, it included contents raising a question about the way of thinking to employ LOS as an index of minimally invasive surgery. Furthermore, the minimally invasiveness of U-VATS was re-evaluated with regard to improvement of the proportion of direct discharge to home after surgery, suggesting that the report is valuable with the possibility to contribute to spreading U-VATS in Nordic countries.

\section{Acknowledgments}

Funding: None.

\section{Footnote}

Provenance and Peer Review: This article was commissioned by the editorial office, Fournal of Thoracic Disease. The article did not undergo external peer review.

Conflicts of Interest: Both authors have completed the ICMJE uniform disclosure form (available at http:// dx.doi.org/10.21037/jtd-20-1386). KH serves as an unpaid editorial board member of Fournal of Thoracic Disease from
Sep 2018 to Aug 2020. The other author has no conflicts of interest to declare.

Ethical Statement: The authors are accountable for all aspects of the work in ensuring that questions related to the accuracy or integrity of any part of the work are appropriately investigated and resolved.

Open Access Statement: This is an Open Access article distributed in accordance with the Creative Commons Attribution-NonCommercial-NoDerivs 4.0 International License (CC BY-NC-ND 4.0), which permits the noncommercial replication and distribution of the article with the strict proviso that no changes or edits are made and the original work is properly cited (including links to both the formal publication through the relevant DOI and the license). See: https://creativecommons.org/licenses/by-nc-nd/4.0/.

\section{References}

1. Hirai K, Takeuchi S, Usuda J. Single-incision thoracoscopic surgery and conventional video-assisted thoracoscopic surgery: a retrospective comparative study of perioperative clinical outcomes. Eur J Cardiothorac Surg 2016;49:i37-41.

2. Shen $Y$, Wang H, Feng M, et al. Single- versus multipleport thoracoscopic lobectomy for lung cancer: a propensity-matched study. Eur J Cardiothorac Surg 2016;49:148-53.

3. Harris CG, James RS, Tian DH, et al. Systematic review and meta-analysis of uniportal versus multiportal videoassisted thoracoscopic lobectomy for lung cancer. Ann Cardiothorac Surg 2016;5:76-84.

4. Ameri MA, Sachs E, Sartipy U, et al. Uniportal versus multiportal video assisted thoracic surgery for lung cancer. J Thorac Dis 2019;11:5152-61.

5. Hirai K, Usuda J. Uniportal video-assisted thoracic surgery reduced the occurrence of post-thoracotomy pain syndrome after lobectomy for lung cancer. J Thorac Dis 2019;11:3896-902.

6. Ng CSH, MacDonald JK, Gilbert S, et al. Optimal approach to lobectomy for non-small cell lung cancer: systematic review and meta-analysis. Innovations 2019;14:90-116.

7. Martin LW, Sarosiek BM, Harrison MA, et al. Implementing a thoracic enhanced recovery program: lessons learned in the first year. Ann Thorac Surg 
2018;105:1597-604.

8. Brunelli A, Thomas C, Dinesh P, et al. Enhanced recovery pathway versus standard care in patients undergoing video-

Cite this article as: Hirai K, Usuda J. A new aspect of advantage on uniportal video-assisted thoracic surgery for lung cancer. J Thorac Dis 2020;12(10):5251-5253. doi: 10.21037/jtd20-1386 assisted thoracoscopic lobectomy. J Thorac Cardiovasc Surg 2017;154:2084-90. 